\title{
Classification of Void Space Types in Fractured-Vuggy Carbonate Reservoir Using Geophysical Logging: A Case Study on the Sinian Dengying Formation of the Sichuan Basin, Southwest China
}

\author{
Kunyu Wang ${ }^{1}$, Juan Teng ${ }^{1, *}$, Hucheng Deng ${ }^{1,2, *}$, Meiyan Fu ${ }^{1,2}$ and Hongjiang Lu ${ }^{1,2}$ \\ 1 College of Energy, Chengdu University of Technology, Chengdu 610059, China; kywang2021@163.com (K.W.); \\ fumeiyan08@cdut.cn (M.F.); luhongiiang@cdut.cn (H.L.) \\ 2 State Key Laboratory of Oil and Gas Reservoir Geology and Exploitation, Chengdu University of Technogy, \\ Chengdu 610059, China \\ * Correspondence: tengjuancugb@outlook.com (J.T.); denghucheng@cdut.cn (H.D.)
}

\section{check for}

updates

Citation: Wang, K.; Teng, J.; Deng, H.; Fu, M.; Lu, H. Classification of Void Space Types in Fractured-Vuggy Carbonate Reservoir Using

Geophysical Logging: A Case Study on the Sinian Dengying Formation of the Sichuan Basin, Southwest China. Energies 2021, 14, 5087. https:// doi.org/10.3390/en14165087

Academic Editors: Wenhao Li, Junqian Li and Pål Østebø Andersen

Received: 29 July 2021

Accepted: 14 August 2021

Published: 18 August 2021

Publisher's Note: MDPI stays neutral with regard to jurisdictional claims in published maps and institutional affiliations.

Copyright: (c) 2021 by the authors. Licensee MDPI, Basel, Switzerland. This article is an open access article distributed under the terms and conditions of the Creative Commons Attribution (CC BY) license (https:/ / creativecommons.org/licenses/by/ $4.0 /)$.

\begin{abstract}
The fractured-vuggy carbonate reservoirs display strong heterogeneity and need to be classified into different types for specific characterization. In this study, a total of 134 cores from six drilled wells and six outcrops of the Deng \#2 and Deng \#4 members of the Dengying Formation (Sichuan Basin, Southwest China) were selected to investigate the petrographic characteristics of void spaces in the fractured-vuggy carbonate reservoirs. Four void space types (VSTs) were observed, namely the solution-filling type (SFT), cement-reducing type (CRT), solution-filling breccia type (SFBT) and solution-enlarging fractures and vugs type (SEFVT). The CRT void spaces presented the largest porosity and permeability, followed by the SEFVT, SFBT and SFT. The VSTs presented various logging responses and values, and based on these, an identification method of VSTs using Bayes discriminant analysis (BDA) was proposed. Two test wells were employed for the validation of the identification method, and the results show that there is good agreement between the identification results and core description. The vertical distribution of VSTs indicates that the SFT and SEFVT are well distributed in both the Deng \#2 and Deng \#4 members. The CRT is mainly found in the Deng \#2 member, and the SFBT occurs in the top and middle of the Deng \#4 member.
\end{abstract}

Keywords: void space type (VST) classification; fractured-vuggy carbonate reservoir; logging data; Sinian Dengying Formation; Sichuan Basin

\section{Introduction}

Carbonate reservoirs can be divided into pore reservoirs, fractured reservoirs, vuggy reservoirs and their mixture combinations, of which the fractured-vuggy reservoirs display a broad prospect for development. The dolomite fractured-vuggy reservoir of the MoxiGaoshiti block in the Sichuan Basin is one of the oldest gas-bearing reservoirs in China, which proved itself as an excellent geological reserve with $5900 \times 10^{8} \mathrm{~m}^{3}$ of gas production in the Anyue gas field by the end of 2020 [1]. Carbonate rock can be characterized by various void spaces, a complex pore structure and cement of the carbonate reservoir [2-8]. For carbonate reservoirs, the inherent heterogeneity and discontinuity [9-11] could improve complexities and consequently result in more difficulties for reservoir prediction.

Void space types and structures are essential for the classification of reservoirs [12-14]. The permeability is strongly related to the complex pore structures $[3,4,8,15]$. The physical properties and productive characteristics of carbonate reservoirs are controlled by two basic pore networks: the interparticle pore network $(r \geq 5 \mu \mathrm{m})$ and the void space network $(\mathrm{r} \geq 100 \mu \mathrm{m})$ [4,16]. For the classification of carbonate reservoirs in previous studies $[3,5,13,15-20]$, the physical properties of carbonates were related to pore types, shapes, and pore-size distribution, whereas most of the micro-scale models focused on non-vuggy 
reservoirs, and the results they acquired are not applicable for the void space network of fractured-vuggy reservoirs.

Various studies have been conducted to study the fractured-vuggy reservoir in the Sichuan basin, mainly focusing on the types of reservoir spaces, the diagenetic history and their controlling factors. Previous studies have divided the reservoir space in the study area into pores, vugs, fractures and their combinations [21-28]. The physical properties of the Dengying Formation reservoir have been discussed [21-28]. The controlling factors of reservoir space are mainly diagenesis, sediments and tectonic activities $[19,25,27-30]$. However, there is a lack of detailed characterization of a certain reservoir space. In this paper, void space, and the relatively effective reservoir space, have been selected in order to describe the characteristics and differences of the pore size, distribution density, porosity and permeability of the four types.

Many researchers are trying to create quantitative relations between the core data and well logs in carbonate reservoirs [31-39]. Geophysical well logging is performed in order to obtain geophysical characteristics such as the electrical conductivity, acoustic properties and radioactivity of rock strata. The application of the logging method can reduce the work of drilling and coring, and quantitatively, or semi-quantitatively, evaluate the geophysical characteristics of the reservoir. To our knowledge, there is still a lack of a reliable quantitative interpretation of fractured-vuggy carbonates. The log responses present the physical properties of minerals, texture, sedimentary structure, and lithofacies of a reservoir, which could also be used for the identification of void spaces in the carbonate reservoir.

In this study, a total of 134 rock samples from six wells were used to measure the density, pore size, porosity and permeability of the different void space types (VSTs). The VSTs of carbonates were identified using the geophysical logging techniques. Bayes discriminant analysis (BDA) was employed to predict the VSTs, with the aid of geophysical logging data, and the results were applied to the classification and prediction of the VSTs in carbonate reservoirs.

\section{Geological Setting}

The Sichuan Basin, located on the southwestern margin of the Yangtze Platform, is a multicycle superimposed basin [40]. The Moxi-Gaoshiti (MG) area was selected as the studied area, which is in the central Sichuan paleo-uplift belt and the eastern axis of the Leshan-Longnvsi paleo-high [28] (Figure 1), and is surrounded by the northern Sichuan depression, the western Sichuan depression, the southwestern Sichuan low-steep belt, thesouthern Sichuan low-steep belt, and the eastern Sichuan high-steep belt. The Sinian Dengying Formation is one of the oldest and best-preserved dolomite carbonate platforms in China, extending from the northeast to the southwest in a warm and shallow marine environment [41,42].

The MG area has experienced multiple phases of tectonic activity, including the Tongwan (Sinian-Early Cambrian), Caledonian (Late Sinian-Silurian), Hercynian (DevonianMiddle Permian), Indosinian (Late Permian-Triassic), Yanshanian and Himalayan (JurassicCenozoic) tectonic activity phases $[43,44]$. The formation of the Sinian carbonate reservoirs was mainly controlled by the Tongwan tectonic activity phase $[42,45,46]$. The Sinian Dengying Formation in the MG area is subdivided into four members, from the oldest to the youngest, and are referred to as the Deng \#1 to Deng \#4. Due to subaerial karstification caused by the Tongwan tectonic uplifts, the upper parts of the Deng \#2 and Deng \#4 members developed dissolved pores and fractures under meteoric water and mixed water $[20,42,44,45]$. This development resulted in these Deng members possessing strong geophysical characteristics, whilst also being favorable for gas exploitation (Figure 1). 


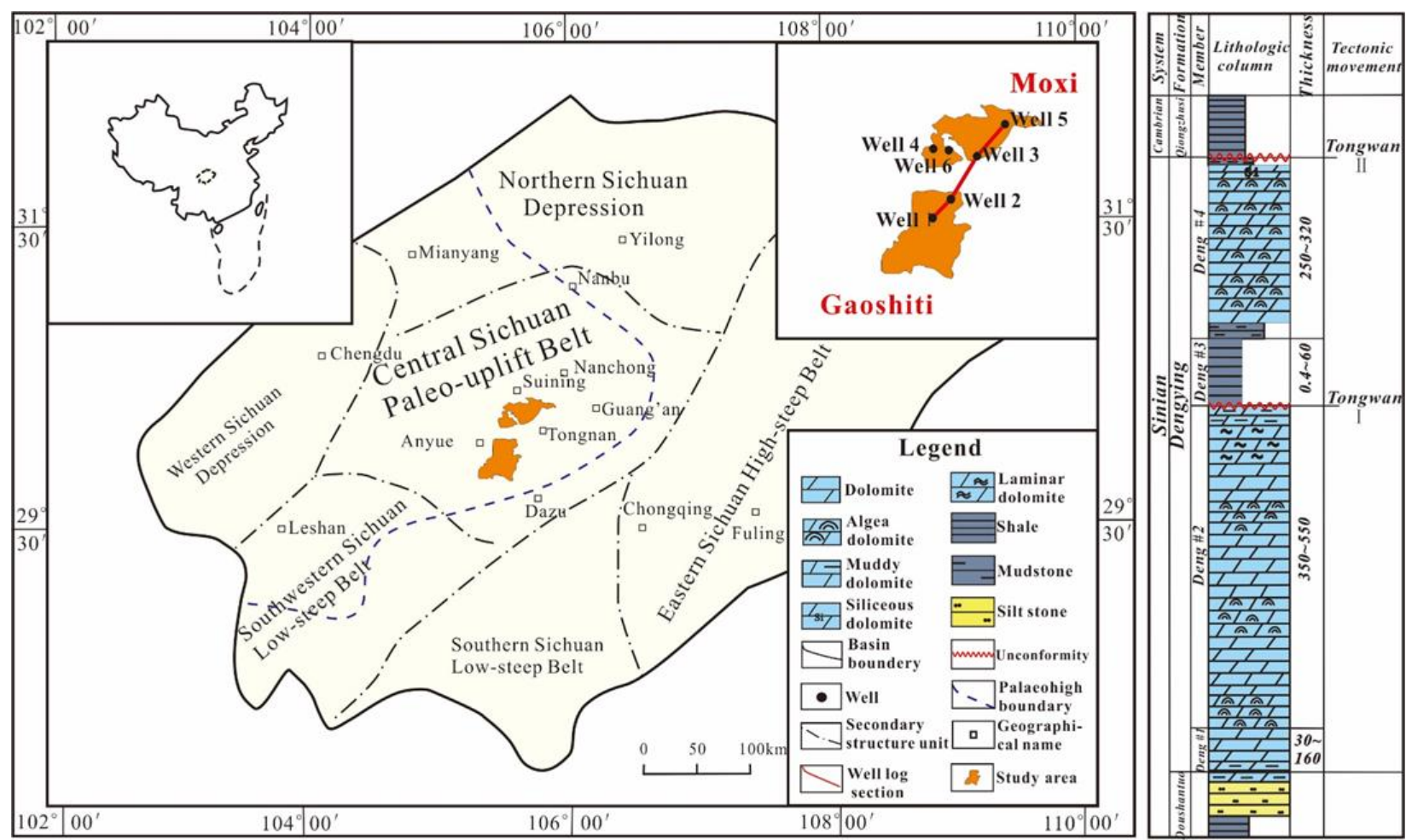

Figure 1. Location map of the study area and schematic of the lithology profile of the Sinian Dengying Formation.

\section{Methodology}

The macroscopic characteristics of VSTs, including the shape, filling condition, pore size, density and distribution, were described. A total of 134 core samples from 6 cored wells (Wells 1-6) (drilled by the Southwest Company of SINOPEC Petroleum Exploration and Production Research Institute) and 6 outcrops (outcrops 1-6) were selected in this study. Full diameter cores were used to directly measure the porosity and permeability, therefore there was 153 samples for porosity measurements, 29 samples for horizontal permeability measurements, and 38 samples for vertical permeability measurements. The porosity of the core samples was measured with the mercury injection method using Boyle's law of porosimetry. The permeability of the core samples was measured the CMS ${ }^{\text {TM}}-300$ Automated Permeameter (Core Laboratories, Netherland). Measuring tape was used to measure the size of VSTs in cores from the 6 Wells (Well \#1 to Well \#6). The sizes of VSTs (including maximum, minimum, and average) were calculated for 338 data of different VSTs. A total of 198 data of different VSTs in the core were counted per $1 \mathrm{~m}$. Logging techniques, including the natural gamma (GR), caliper (CAL), double lateral resistivity logs (RD and RS), density (DEN), neutron logging (CNL), and sonic-interval transit time (AC), were chosen for the identification of void space types. The logging data of GR, CAL, DLL, DEN, CNL and AC were then extracted with a vertical resolution of $0.125 \mathrm{~m}$. Formation micro-resistivity images (FMIs) were combined with logging data for the identification of void space types.

\section{Results}

The space in carbonate reservoirs is composed of matrix pores and void spaces. In our study, matrix pores had low average porosity $(1.52 \%)$ and permeability $(0.11 \mathrm{mD})$, which could be the barrier for fluid flow during hydrocarbon exploitation. Void spaces, having more storage space, could enhance the capacity of fluid flow during fluid exploitation. In this study, void spaces were the key targeted pore type. Based on the effect of diagenesis on pore evolution, void spaces in 134 cores from the Deng \#2 and Deng \#4 members were described, and the results show that the void spaces in the studied area were composed of four types, including solution-filling type (SFT), cement-reducing type 
(CRT), solution-filling breccia type (SFBT) and solution-enlarging fractures and vugs type (SEFVT) void spaces.

\subsection{Morphology Characteristics of VSTs}

On the surface of cores, the SFT void spaces are distributed along the bedding plane (Figure 2a). The SFT void spaces have an ellipsoidal shape and are widely developed and distributed along the algal-rich bedding plane in outcrop \#4, outcrop \#5 and outcrop \#6 (Figure 3a). Based on the investigation of outcrops, the SFT void spaces are widely developed in each layer, especially in the Deng \#2 and Deng \#4 members. The SFT void spaces had small pore sizes, which ranged from 1 to $50 \mathrm{~mm}$, and mainly from 1 to $2 \mathrm{~mm}$ (Figure 4a).
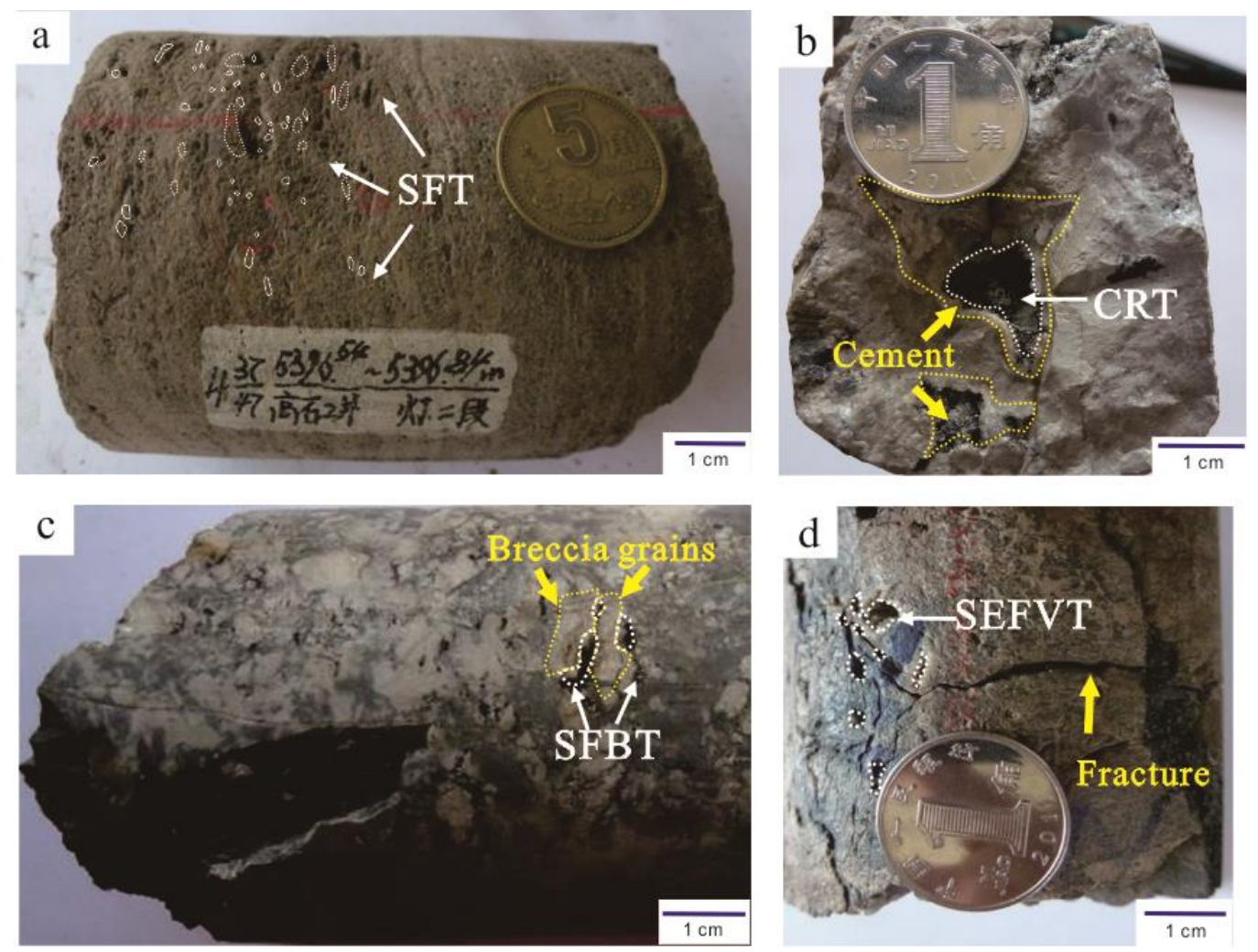

Figure 2. Typical macroscopic characteristics of void space types in cores: (a) solution-filling type (SFT) void spaces in a core sample from Well \#2 at depth from 5396.54 to $5396.84 \mathrm{~m}$-the white circles show the millimeter-sized pores along the core bedding; (b) cement-reducing type (CRT) void spaces in a core sample from Well \#1 at depth from 4962.15 to $4962.24 \mathrm{~m}$-the cement-reducing type (CRT) (inside the white circle) is surrounded by the multiple- period dolomite cement (yellow circle); (c) solution-filling breccia type (SFBT) void spaces in a core sample from Well \#1 at depth from 4978.12 to $4978.23 \mathrm{~m}$-pores are enclosed between the breccia grains; (d) solution-enlarging fractures and vugs type (SEFVT) void spaces in a core sample from Well \#6 at depth from 5102.12 to $5102.23 \mathrm{~m}$, showing the pores distributing along the fractures. 


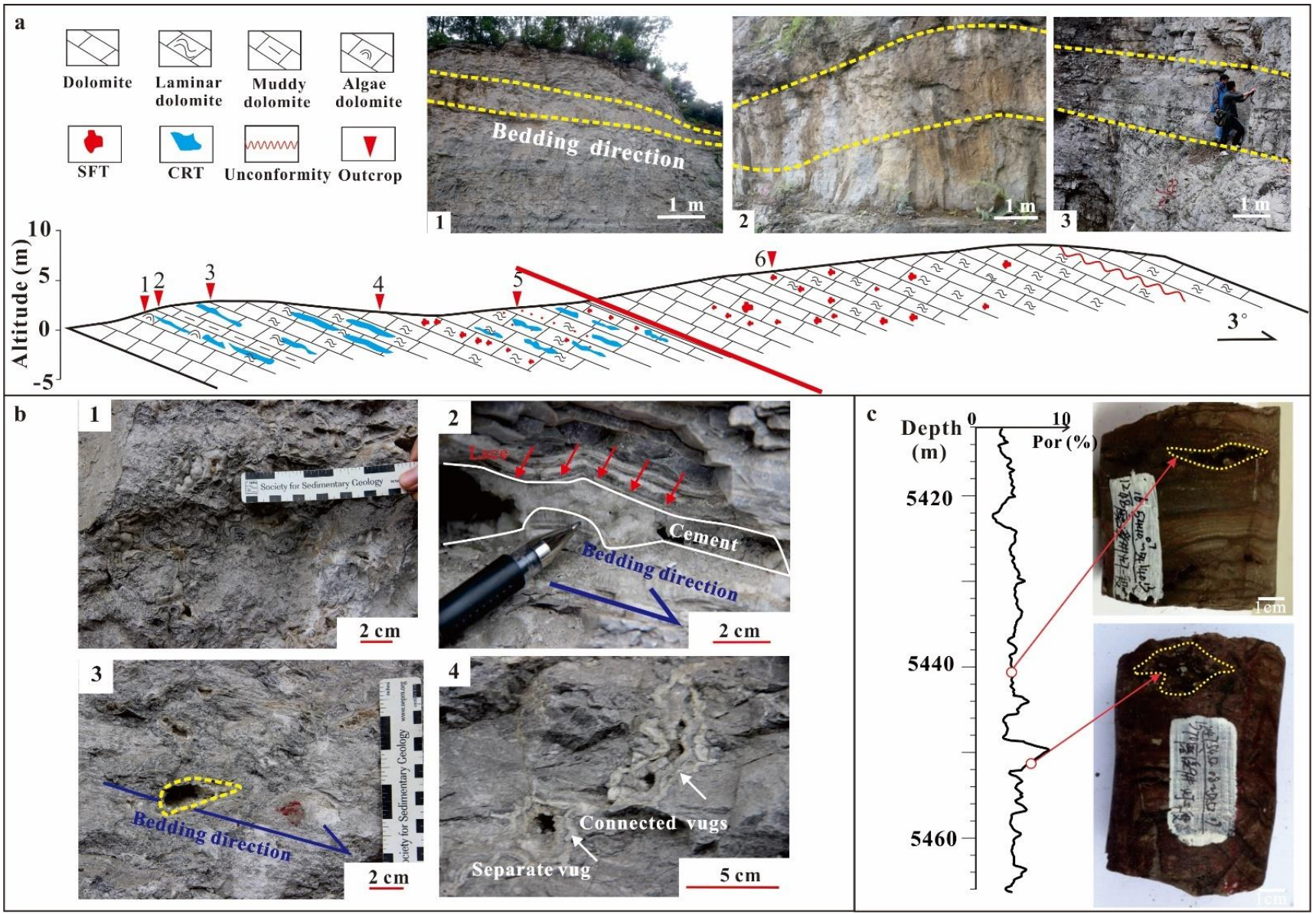

Figure 3. Features of solution-filling type (SFT) and cement-reducing type (CRT) in Deng \#2 observed from outcrops. (a) Along-bedding distribution of solution-filling type (SFT) and cement-reducing type (CRT). The cement-reducing type (CRT) (left) and solution-filling type (SFT) (right) are distributed in the lower and upper Deng \#2 member, respectively; (b) morphology of cement-reducing type (CRT); (c) filling features of the cement-reducing type (CRT).
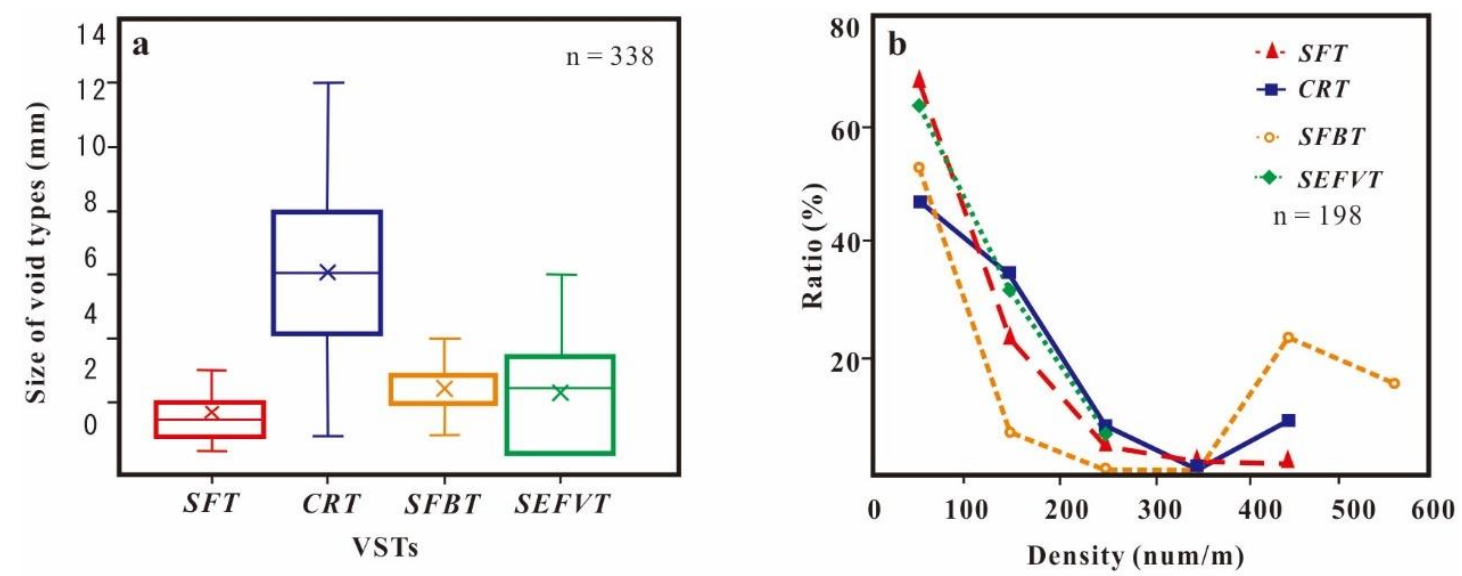

Figure 4. Characteristics of void space types (SFT:solution-filling type; CRT:cement-reducing type; SFBT:solution-filling breccia type; SEFVT:solution-enlarging fractures and vugs type) in cores: (a) the pore diameter; (b) the density observed.

The CRT void spaces present isopachous rims consisting of the microorganism laminae and cementations. Each dark lamina had a thickness of approximately $0.1-1 \mathrm{~mm}$ (Figure 2b). The CRT void spaces were formed during the Icehouse period, when the Yangtze region was in the aragonite sea environment [46], and bacteria and algae were very abundant $[24,47,48]$, which is favorable for the formation of microorganism laminae in the algae-rich dolomite 
rock. Due to the rise in sea levels, the CRT void spaces were cemented from the edge toward the interior of the residual vugs by dolomite crystals [49-51], which was the major factor in reducing the storage space. The CRT void spaces observed in outcrop \#1 demonstrated a shape of "clusters of grapes" (Figure $3 b(1)$ ), and were distributed along the bedding plane under the lateral section view in outcrop \#3 (Figure $3 b(2)$ ), or the isolated oblique to the bedding in the cross-section view in outcrop \#2 and outcrop \#1 (Figure 3b(3,4)). Based on the porosity tests, the filling degree of CRT void spaces in the Deng \#2 member decreases as the burial depth increases (Figure 3c). The CRT had relatively large pore sizes, which were generally 4 to $8 \mathrm{~mm}$ (Figure $4 \mathrm{a}$ ).

The irregular-shaped SFBT void spaces are mainly developed in karst breccia dolomites (Figure 2c), which were strongly eroded and collapsed due to supergene corrosion during the Tongwan tectonic activity phase II [20-23,52]. The SFBT void spaces are relatively low in abundance and unevenly distributed in outcrops. The dominant pore sizes of the SFBT were commonly 2 to $3 \mathrm{~mm}$ (Figure $4 \mathrm{a}$ ).

The SEFVT void spaces displayed various angles of fractures and connection patterns between the fractures and vugs. The vugs were developed through fractures, or along the sides of fractures, presenting a string-beaded form (Figure 2d).

In the cores, more than $80 \%$ of SFT, CRT and SEFVT had a density less than $200 \mathrm{num} / \mathrm{m}$. In the Deng \#4 member, SFBT density was mainly distributed in ranges of less than 100 num $/ \mathrm{m}$ and 400 to $600 \mathrm{num} / \mathrm{m}$, with $54 \%$ of sample points located in the first range and $38 \%$ in the latter (Figure $4 \mathrm{~b}$ ).

\subsection{Physical Properties of VSTs}

The porosity of SFT is mainly from $1 \%$ to $3 \%$, whereas the porosity of CRT is from $2.5 \%$ to $3.5 \%$ (Figure 5). The SFBT and SEFVT have a porosity from $1.5 \%$ to $4.0 \%$, of which $71.28 \%$ of the SFBT and $80 \%$ of the SEFVT are in this range, respectively. Overall, the CRT has the relatively highest porosity, followed by the SEFVT, SFBT, SFT.
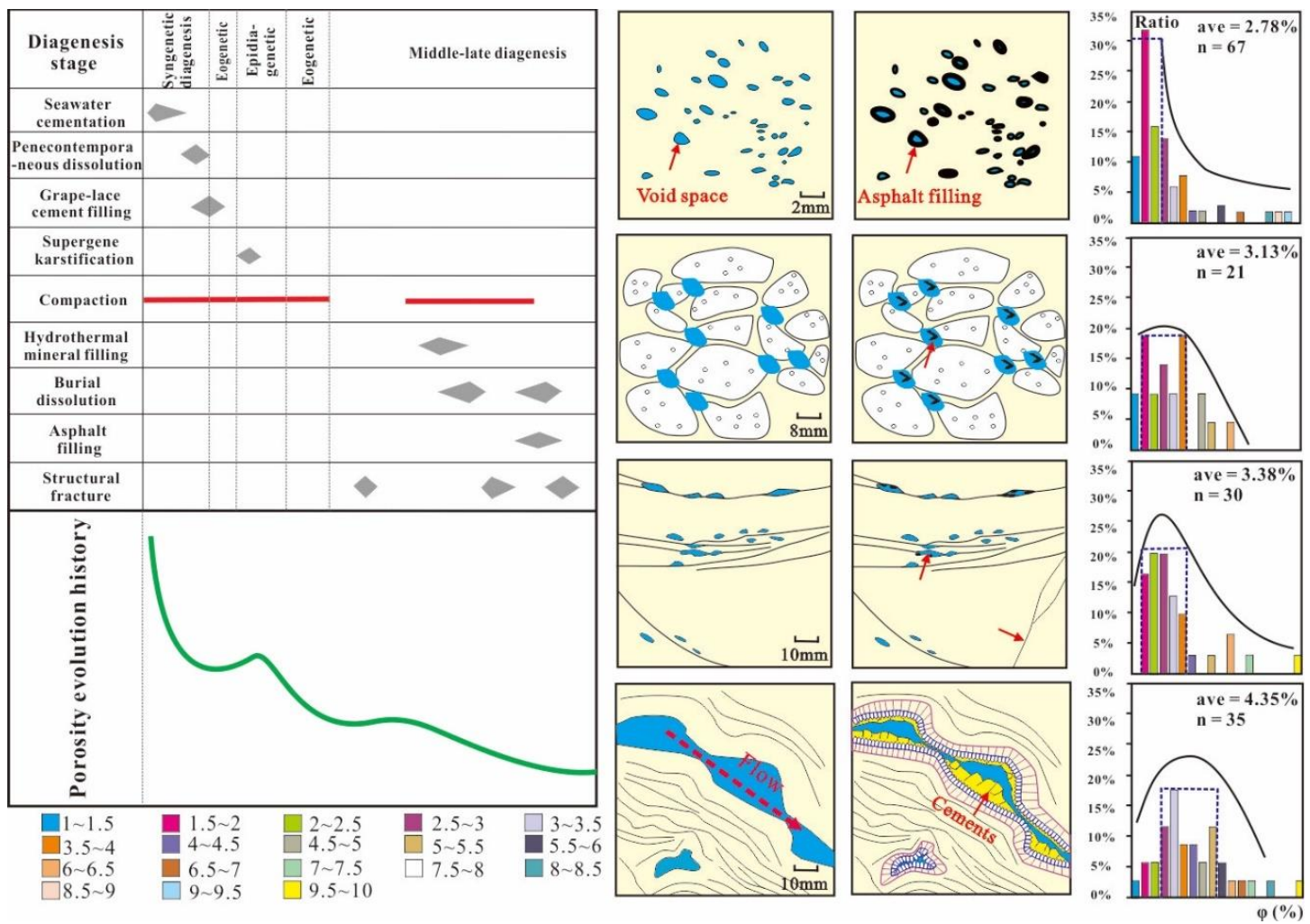

Figure 5. Diagenetic sequence and frequency distribution of porosity of four types (diagenetic sequence was revised from [53]). 
The permeability of SFTs is mainly between $10^{-3}$ and $10^{-2} \mathrm{mD}$. The horizontal permeability of CRT has the largest value of 1 to $10 \mathrm{mD}$ (accounting for approximately $91.10 \%$ of all the samples), which is larger than the vertical permeability by one order of magnitude at the same depth (Figure 6a). For example, the botryoidal residual structure section of Well \#3, having a horizontal permeability of $5.46 \mathrm{mD}$ and a vertical permeability of $2.08 \mathrm{mD}$, indicates that the connection in the lateral direction is better than that in the longitudinal direction. The SFBT and SEFVT have close permeability, from $10^{-1}$ to $10 \mathrm{mD}$, whereas the SFBT has a larger mean permeability than the SEFVT. The SEFVT also shows larger horizontal permeability than vertical permeability, which could be due to the development of horizontal fractures.
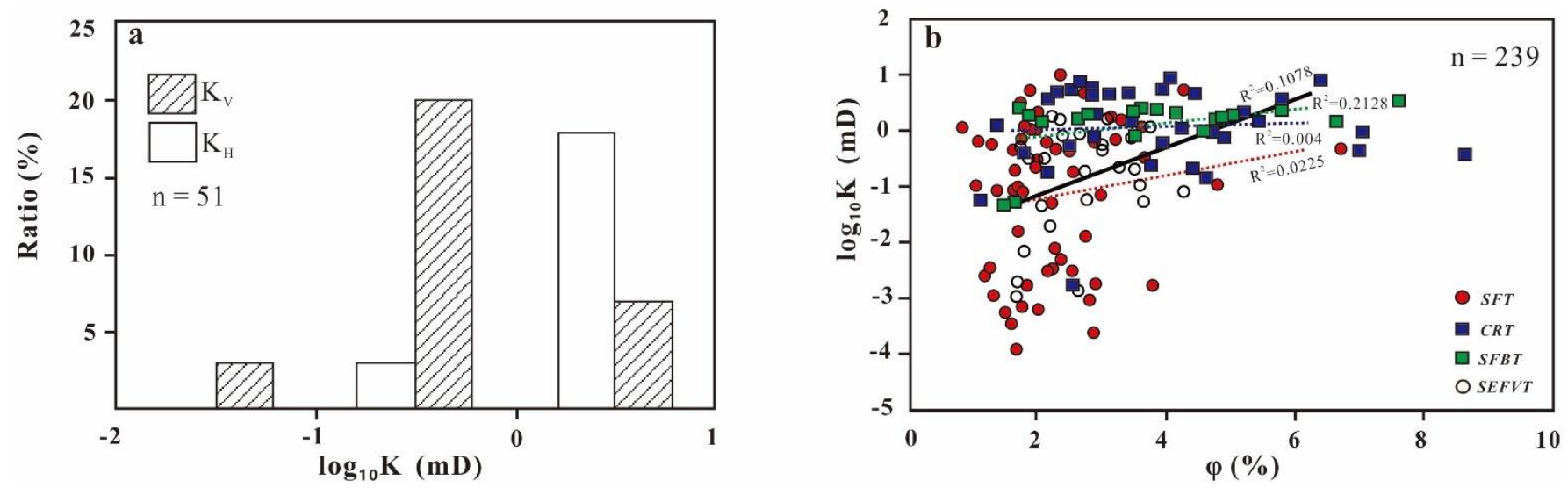

Figure 6. Features of permeability of void space types (SFT: solutionfilling type; CRT: cement-reducing type; SFBT: solutionfilling breccia type; SEFVT: solution-enlarging fractures and vugs type): (a) the vertical and horizontal permeability of cement-reducing type (CRT); (b) correlation between porosity and the logarithm of permeability.

Normally, the permeability is correlated with interparticle or intercrystal porosity, whereas the relationship between the porosity and permeability of the Dengying Formation reservoirs is weakly correlated (Figure 6b), which could be the effect of the complex void space system used during the diagenesis and deposition [16,22,23,25,52]. A large number of isolated dissolved pores were formed with poor connectivity. As Figure $6 \mathrm{~b}$ shows, the cross-plot of CRT and SFBT reveals that high porosity does not promise high permeability. A relatively strong relationship between porosity and permeability of the SEFVT is shown in Figure 6b, which could be caused by microfractures.

The effective output results indicate that CRT has the best gas output per meter of core length (Figure 7). The strong performance of this type can be attributed to its good storage space and physical properties. The SEFVT has the median output, and the production capacity of the SFT is the poorest. 


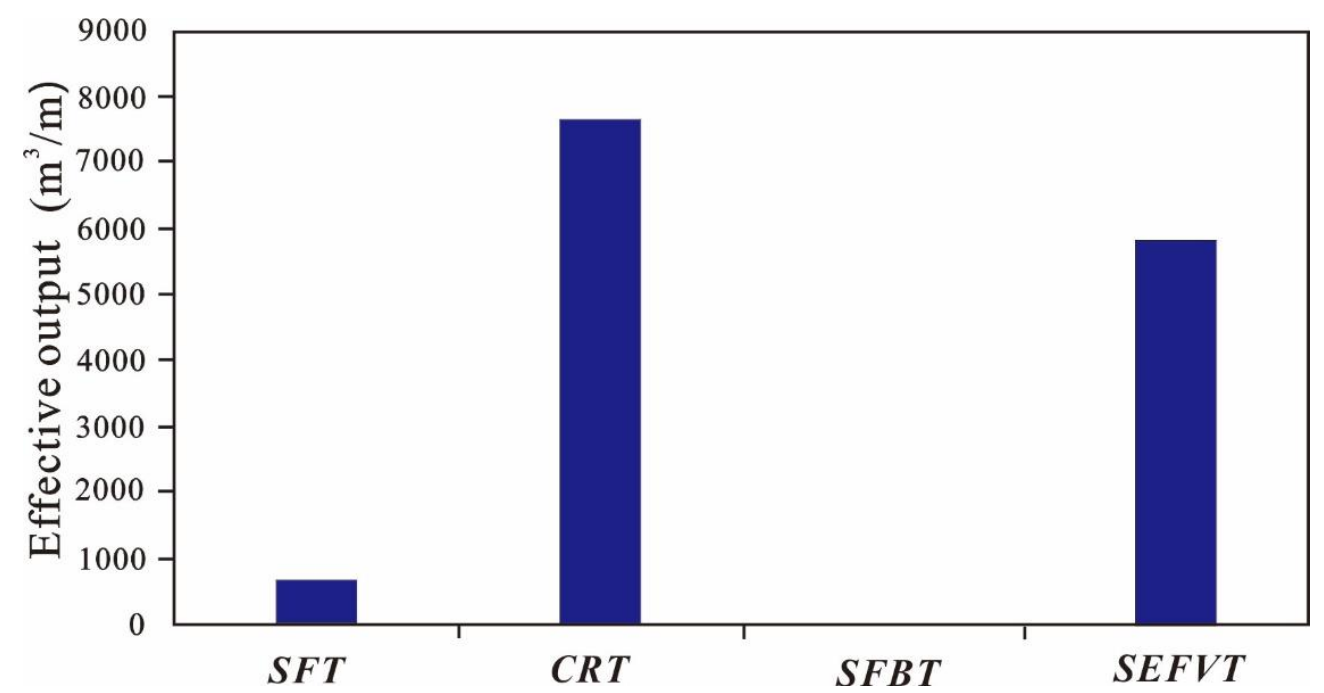

Figure 7. Variation of gas output of four void space types (SFT:solution-filling type; CRT:cement-reducing type; SFBT:solution-filling breccia type; SEFVT:solution-enlarging fractures and vugs type).

\subsection{Logging Responses of VSTs}

A vertical resolution of $1 \mathrm{~m}$ of the FMI logging is employed. Four sections from five wells were selected for the identification of VSTs, and these read as 4962-4962.8 m from Well \#1, 5430-5431.8 m from Well \#4, 4976.2-4978 m from Well \#1 and 5112-5113.8 m from Well \#3. The SFT shows a dark "honeycomb" pattern in the bright background (Figure 8a), which indicates that there were numerous solution-filled void spaces in the matrix dolomites. The petal-like dark feature of the CRT (Figure $8 \mathrm{~b}$ ) is created by extensive dissolution during subaerial exposure. The SFBT, characterized by disorderly dark spots and short lines (Figure 8c), indicates interconnected channels among sharp fragments of breccia grains. The dark sinusoidal lines of SEFVT shows width-enlarged ( $>2 \mathrm{~mm}$ in width) diagonal fractures in FMIs (Figure 8d).
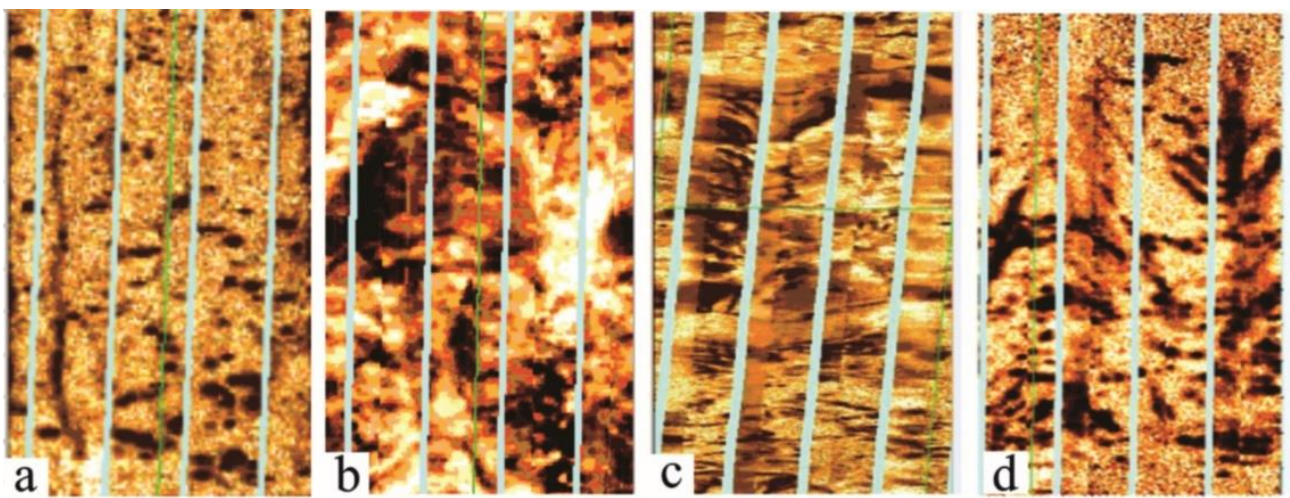

Figure 8. FMI logging characteristics of four void space types: (a) solution-filling type; (b) cementreducing type; (c) solution-filling breccia type; (d) solution-enlarging fractures and vugs type.

The logging values of the four VSTs are shown in Table 1 . The SFT and CRT can be distinguished from the SFBT and SEFVT because of the high average CNL values of SFT and CRT (3.842\% 9.425\%). The average DLL values of the SFT are relatively higher than that of the other VSTs, resulting in significant differences between the SFT and CRT. The tri-porosity logging (DEN, AC and CNL), reflecting the occurrence of void spaces, and GR and CAL logging, demonstrating filling degree, were combined to distinguish these VSTs. Although the CAL logging does not show obvious changes, when the VSTs are half-filled or unfilled, it increases slightly. 
Table 1. Range and average of logging values of void space types (SFT—solution-filling type; CRT—cement-reducing type; SFBT—solution-filling breccia type; SEFVT—-solution-enlarging fractures and vugs type).

\begin{tabular}{|c|c|c|c|c|c|c|c|}
\hline Type & $\mathrm{AC}(\mu \mathrm{s} / \mathrm{m})$ & CAL $(\mathrm{cm})$ & CNL (\%) & $\operatorname{DEN}\left(\mathrm{g} / \mathrm{cm}^{3}\right)$ & GR (API) & $\operatorname{RD}^{1}(\Omega \cdot m)$ & $\mathrm{RS}^{1}(\Omega \cdot \mathrm{m})$ \\
\hline SFT & $\underline{45.334-52.684}$ & $\underline{6.302-6.594}$ & $\frac{3.842-7.078}{5560}$ & $2.659-2.832$ & $\frac{11.272-14.203}{1272}$ & $\frac{652.000-15474.160}{806200}$ & $561.377-3579.652$ \\
\hline CRT & $45.652-52.643$ & $6.170-448.652$ & $\begin{array}{r}5.560 \\
4.176-9.425 \\
\end{array}$ & 2.637746 .871 & $\begin{array}{l}12.738 \\
10.262-17.517 \\
\end{array}$ & $\begin{array}{r}8063.08 \\
570.284-3043.968 \\
\end{array}$ & $\begin{array}{l}232.7830 .515 \\
232.791 .534 \\
\end{array}$ \\
\hline SFBT & $\begin{array}{l}46.379 .148 .429 \\
4\end{array}$ & $\begin{array}{r}6.411 \\
6.300-6.800 \\
\end{array}$ & $\begin{array}{r}6.800 \\
0.742-3.578 \\
\end{array}$ & $\begin{array}{r}2.754 \\
2.746-2.799 \\
\end{array}$ & $\begin{array}{c}13.890 \\
10.072-16.272 \\
\end{array}$ & $\begin{array}{r}1807.126 \\
936.422-5145.797 \\
\end{array}$ & $\begin{array}{r}512.1585 \\
518.766-3233.535 \\
\end{array}$ \\
\hline SEFVT & $\frac{44.824-47.237}{46}$ & $\frac{5.870-551}{5.898}$ & $\frac{0.191-3.771}{1.980}$ & $\frac{2.710-2.899}{2.804}$ & $\frac{12.757-21.014}{16.890}$ & $\frac{965.882-3649.836}{2307.859}$ & $\frac{1151.992-3886.6924}{2519.342}$ \\
\hline
\end{tabular}

${ }^{1} \mathrm{RD}$ and RS are the deep and shallow laterolog resistivity, respectively.

\subsection{Identification Process of VSTs Using Logging Data}

Bayes discriminant analysis (BDA) was used for the quantitative interpretation of the VST distribution in fractured-vuggy carbonate reservoirs. The logging datasets (i.e., GR, CAL, DLL, AC, DEN and CNL) of each VSTs were used as the input variables for establishing the linear discriminant equations. The Bayes discriminant analysis in this study was performed using the Statistical Product and Service Solutions (SPSS) software. On the basis of the known VSTs of cores or FMIs, the logging data of five wells (Well \#1, Well \#2, Well \#4, Well \#9, Well \#10) corresponding to these types were selected. Before performing BDA on the well log responses, all the data were normalized. In this study, the logging data of Well \#1 was used as the standard well for logging standardization (Figure 9). The types of the fractured-vuggy carbonates can be identified based on the principle of the maximum posterior probability of the Bayes discriminant. The cross-validation results (Table 2) suggest that the identification accuracy of the SFT, CRT, SFBT and SEFVT is $80.8 \%$, $80.0 \%, 93.7 \%$ and $100 \%$, respectively, which indicates that the Bayes discriminant analysis is valid for the VSTs' identification.

The validation test evaluates classification performance using two independent samples of data. The interval in Well \#3 was $200 \mathrm{~m}$ in the Deng \#4member, while the interval in Well \#5 was $60 \mathrm{~m}$ in the Deng \#2 member were chosen for the validation test, and the validation results are shown in Figure 10. The validation column consists of cores and FMIs. The VSTs including SFT, SFBT and SEFVT alternately appear in the Deng \#4 member, whereas the CRT is only present in the Deng \#2 member. Thick SFT and SEFVT layers are common from top to bottom in the Deng \#4 member. The SFBT appear as thin layers in the upper and lower parts of the Deng \#4 member. In general, good agreement is shown between the identification results using discriminant analysis and core samples. However, uncertainties arose in the error areas located in the middle of the intervals. The horizontal fractures of the bedding plane were mistaken for the SEFVT, which inevitably affected the identification by the logging results. Although the discrimination errors require improvement, the results of the BDA are still applicable for predicating VSTs in other wells in the study area.

According to the BDA results of four wells (Well \#1, Well \#2, Well \#3, Well \#5), the vertical distribution of VSTs is shown in Figure 11. The SFT is efficiently distributed in each well, followed by the SEFVT. The CRT presents itself in the thick layers, and is only shown in the Deng \#2 member of Well \#5, which could result from the relatively strong Tongwan tectonic activity phase I in the northeastern MG gas field. The SFBT appears thin in the upper and middle parts of the Deng \#4 member of Well \#1 and Well \#3. The vertical distribution of multiple VSTs demonstrates high heterogeneity in fractured-vuggy reservoirs. 


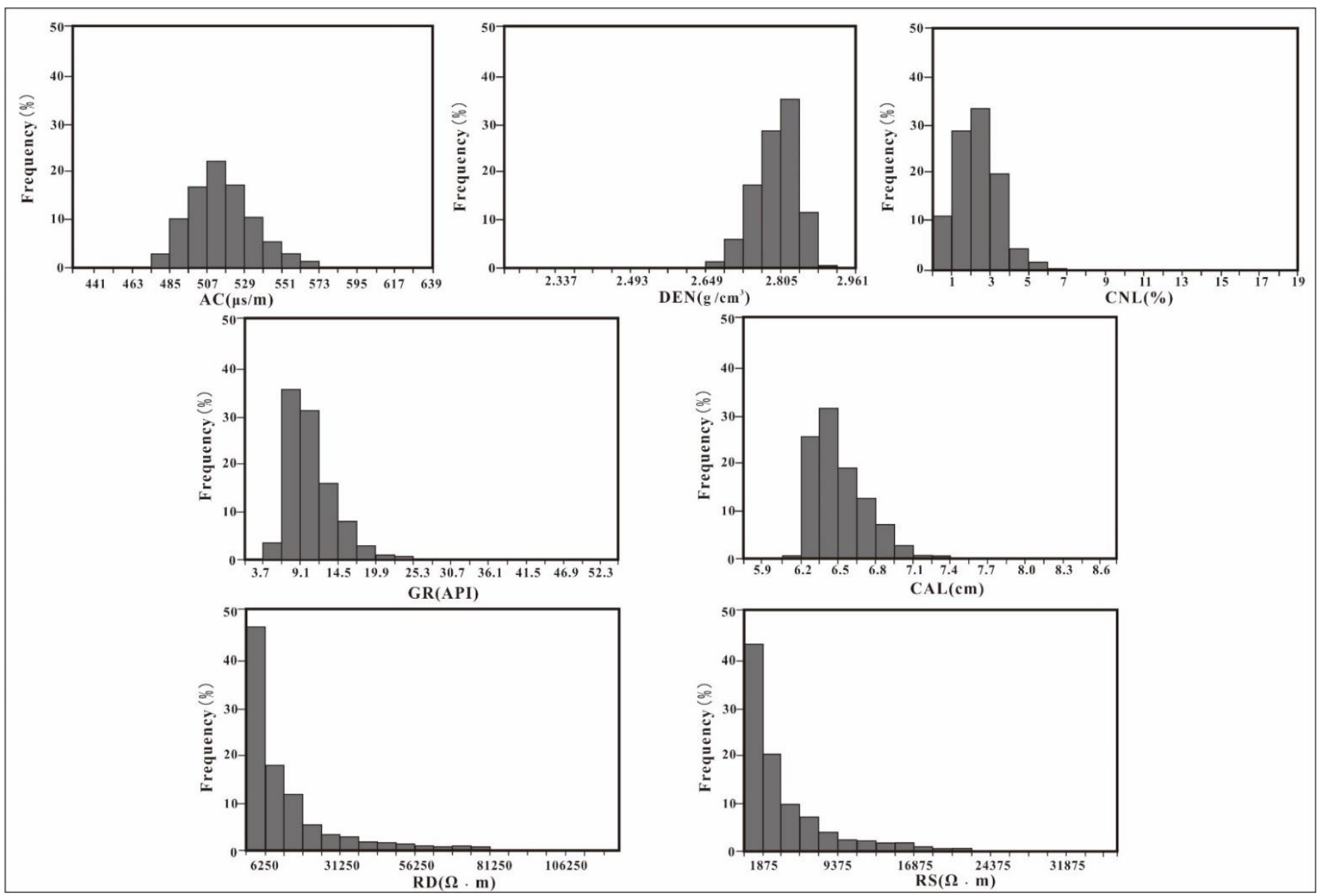

Figure 9. Distribution of logging data of AC, DEN, CNL, GR, CAL, RD and RS of Well\#1 in the study area.

Table 2. Classification results of the void spaces of the MG carbonate reservoirs (SFT:solutionfilling type; CRT:cement-reducing type; SFBT:solution-filling breccia type; SEFVT:solution-enlarging fractures and vugs type).

\begin{tabular}{cccccc}
\hline \multirow{2}{*}{ VSTs } & \multicolumn{5}{c}{ Predicted Group Membership } \\
\cline { 2 - 6 } & SFT & CRT & SFBT & SEFVT & Percent Correct \\
\hline SFT & 80.8 & 19.2 & 0 & 0 & $80.8 \%$ \\
CRT & 13.3 & 80.0 & 6.7 & 0 & $80 \%$ \\
SFBT & 6.7 & 0 & 93.3 & 0 & $93.7 \%$ \\
SEFVT & 0 & 0 & 0 & 100 & $100 \%$ \\
\hline
\end{tabular}




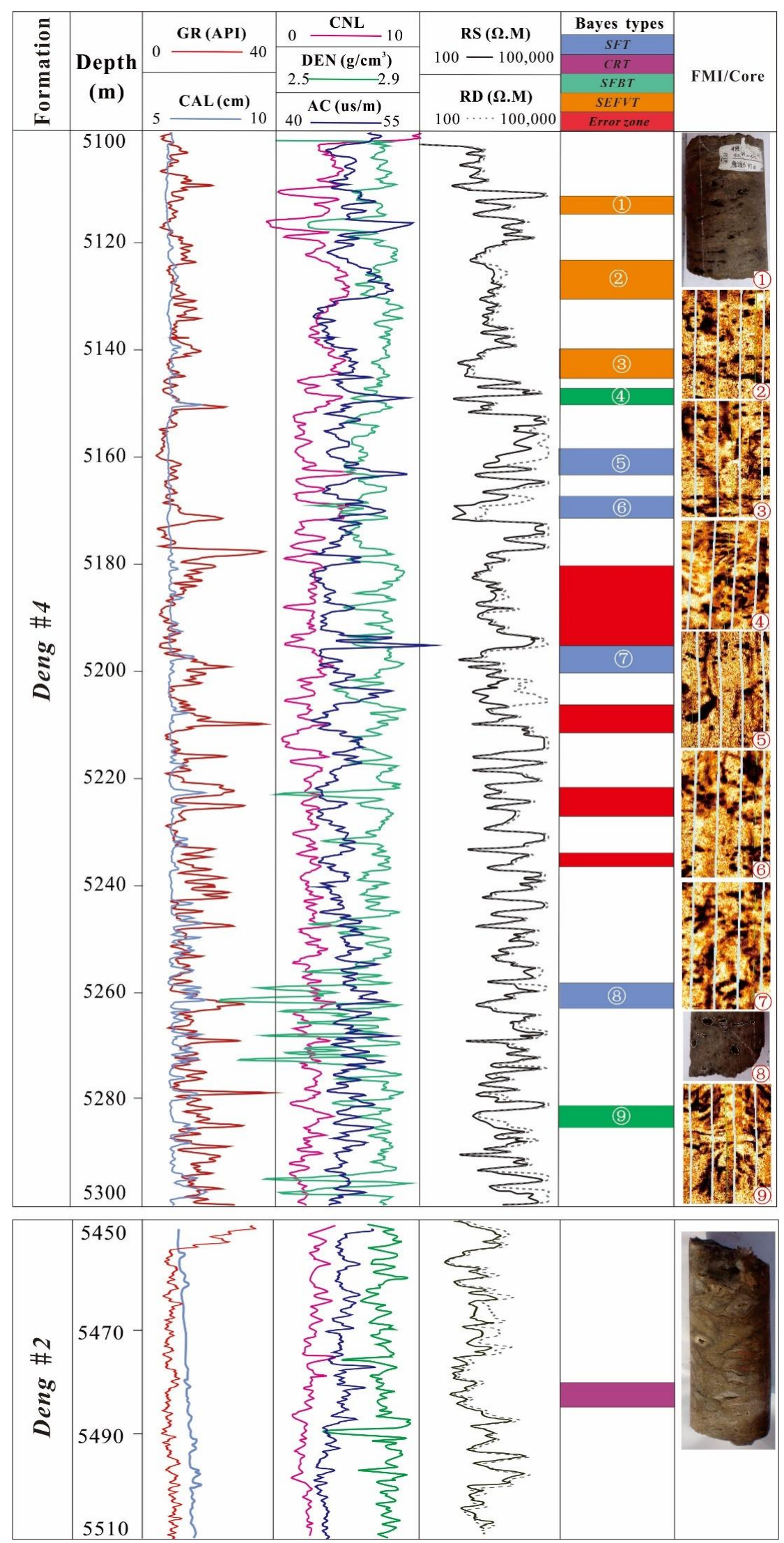

Figure 10. Comparison of identification and FMI/core results of two intervals of the Deng \#4 (depth of 5100 and $5300 \mathrm{~m}$ from Well \#3) and Deng \#2 (depth of 5450 and $5510 \mathrm{~m}$ from Well \#5). 


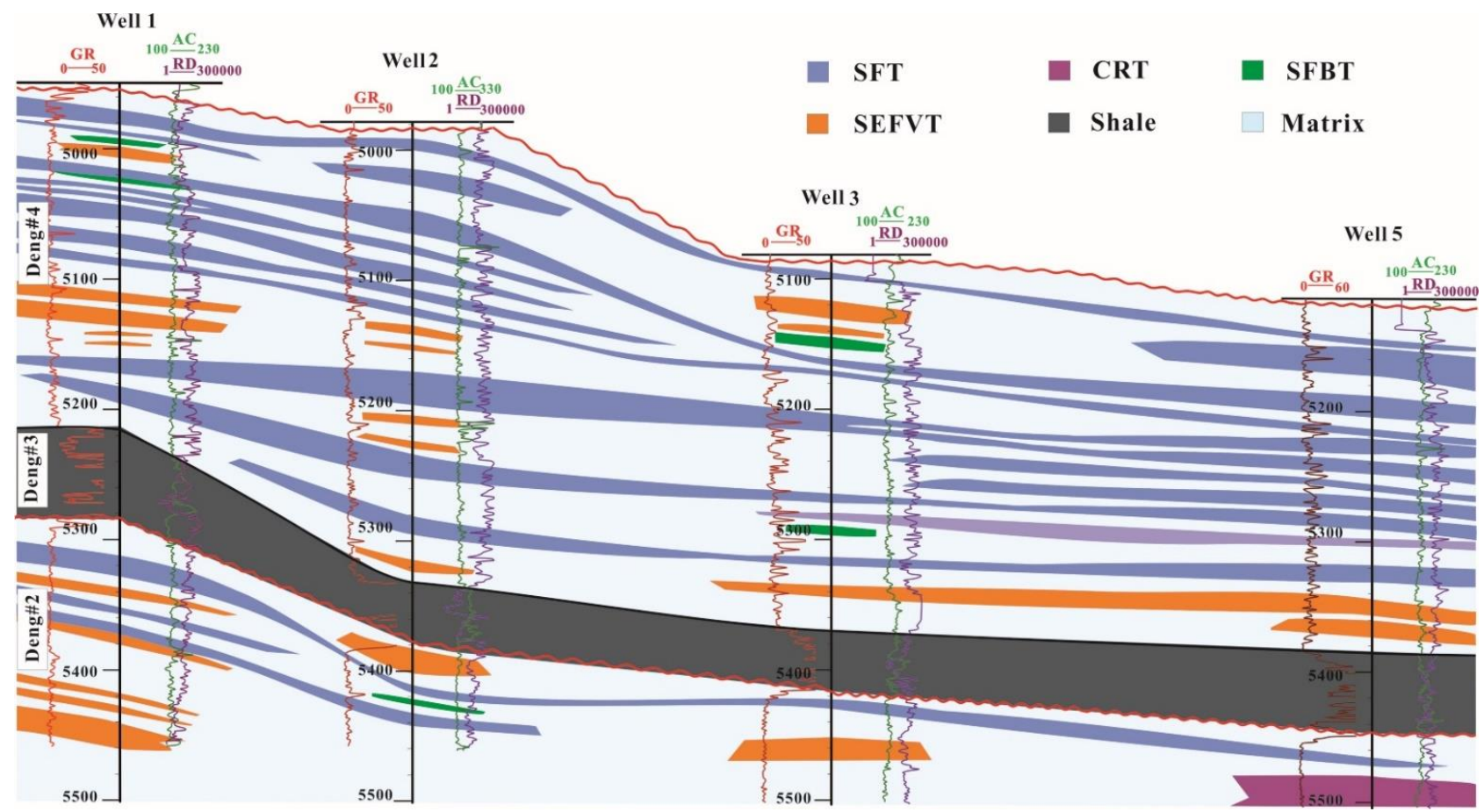

Figure 11. Vertical distribution of void space types in a cross-section in the MG block. (SFT: solution-filling type; CRT: cement-reducing type; SFBT: solution-filling breccia type; SEFVT: solution-enlarging fractures and vugs type).

\section{Discussions}

The results of the VSTs classification are summarized in Tables 1 and 3. The deeply burial dolostones have experienced successive diagenesis, such as subaerial karstification during the Tongwan tectonic activity phase, cementation and filling, and dissolution by thermal fluid in the deep-burial environment, which has strongly influenced the porosity and pore size distribution of VSTs (Figures 4 and 5). Furthermore, the differences in the logging characterization of the VSTs correspond to their density, pore size and physical properties (Tables 1 and 3 ).

Table 3. Range and average of pore size, density and physical properties of void space types (SFTsolution-filling type; CRT—cement-reducing type; SFBT—solution-filling breccia type; SEFVTsolution-enlarging fractures and vugs type).

\begin{tabular}{ccccc}
\hline & SFT & CRT & SFBT & SEFVT \\
\hline Pore size (mm) & $\frac{0.5-10}{1.71}$ & $\frac{1-30}{8.2}$ & $\frac{1-4}{2.49}$ & $\frac{0.5-6}{2.34}$ \\
Density (num/m) & $\frac{3.70-460}{101}$ & $\frac{16.67-475}{124}$ & $\frac{7.14-588.89}{219}$ & $\frac{1.75-206.67}{63}$ \\
Porosity (\%) & $\frac{0.82-9.03}{2.78}$ & $\frac{1.23-9.88}{4.35}$ & $\frac{1.17-6.04}{3.13}$ & $\frac{1.63-9.88}{3.38}$ \\
Permeability (mD) & $\frac{0.0001-9.720}{0.853}$ & $\frac{0.002-8.005}{1.974}$ & $\frac{0.026-3.077}{0.650}$ & $\frac{0.001-1.870}{0.494}$ \\
\hline
\end{tabular}

The SFT void spaces were formed due to further dissolution and expansion of interpartical pores and intercrystal pores during the Tongwan epoch. However, SFT void spaces were greatly affected by being filled with siliceous fluid, or with asphalt in later diagenesis [27,50], resulting in the worst porosity. The SFT has relatively small pore size and low porosity, but high AC and CNL values, which could result from the high density of SFT void spaces. The SFT has the highest DLL values, because the trapped gas in the SFT could increase resistivity.

The cementation related to the CRT has three phases successively: fibrous-shaped dolomite cements in the first phase of cementation, blade-shaped dolomite cements in the second phase of cementation and crystal dolomite cements in the third phase of 
cementation [25,53,54] (Figure 5). Although cemented by botryoidal calcite, the CRT underwent long-term meteoric water dissolution, resulting in good porosity. The CRT corresponds to high AC and CNL responses and low DEN responses, which results from relatively high porosity and permeability. The low GR values and the abnormally high DLL values indicate that the CRT void spaces may be filled by crystal cement instead of mud.

The SFBT has the highest CAL values due to breccia rocks collapsing and the diameter of the borehole enlarging. The fractures in fragile and soluble dolomites were dissolved and enlarged due to the downward seepage of meteoric water during the Tongwan tectonic activity phase. Although the SEFVT and the SFBT have similar physical properties, due to the relatively low filling degree by the Himalayan tectonic activity phase [22], and the following influences by organic acid fluid [46], the SEFVT void spaces were better preserved than the SFBT void spaces. The low DLL logging data of the SEFVT indicate the existence of diagonal fractures of the SEFVT.

\section{Conclusions}

The fractured-vuggy carbonate reservoirs have various pore types, which demonstrate different capacities for gas storage. The description and prediction of VSTs could contribute to the exploration and development of natural gas in the fractured-vuggy carbonate reservoirs. In order to predict the VSTs and their distribution in the fractured-vuggy carbonate reservoirs of the ancient Dengying Formation in the Moxi-Gaoshiti (MG) block, in central Sichuan Basin, Southwest China, a classification method using geophysical logging techniques was proposed in this study. Specific conclusions are as follows:

(1) Four VSTs in carbonate fractured-vuggy reservoirs were observed, including the SFT, CRT, SFBT and SEFVT. The CRT has the largest porosity and permeability, whereas the SFT void spaces are characterized by the worst porosity and permeability. The SFBT and SEFVT have close physical properties. There appears a better relationship between the porosity and permeability of the SEFVT than the SFBT presents, which could be caused by microfractures.

(2) Each VST shows different responses on the FMIs. The SFT shows a dark "honeycomb" pattern. The CRT presents petal-like dark features. The SFBT is characterized by disorderly dark spots and short lines. Dark sinusoidal lines appear in SEFVT. The high DLL values in the SFT and high AC and CNL values could help to distinguish CRT from SFBT and SEFVT. The SFBT corresponds to CAL values due to breccia rocks collapsing, and the GR values show the filling degree in SEFVT.

(3) The BDA were used for the classification of VSTs using logging data. The results of the BDA were applied in the case study (Well \#3 and Well \#5), and there is good agreement between the identification results and the core and FMI results, indicating that the proposed method is valid for VST identification and prediction.

(4) The void spaces in the Deng \#2 and Deng \#4 developed four VSTs, which were contained in an interbedded pattern displaying the SFT and SEFVT in each layer, with the CRT positioned in the thick layer in Deng \#2, and the SFBT in the top and middle of the Deng \#4.

Author Contributions: Investigation, methodology, writing-original draft, data curation, K.W.; writing-review and editing, J.T.; review and editing, funding acquisition, H.D.; review and editing, M.F.; funding acquisition, H.L. All authors have read and agreed to the published version of the manuscript.

Funding: This research was supported by Southwest Company of SINOPEC Petroleum Exploration and Production Research Institute from Development Mechanism of Fractured-vuggy Reservoir in Carbonate Gas Reservoir in Sinian System Project (XNS14JS2013-035). The permission to use the well data were stated by the Southwest Company of SINOPEC Petroleum Exploration and Production Research Institute.

Institutional Review Board Statement: Not applicable. 
Informed Consent Statement: Written informed consent has been obtained from the patient(s) to publish this paper.

Data Availability Statement: The study did not report any data.

Acknowledgments: This research was supported by Southwest Company of SINOPEC Petroleum Exploration and Production Research Institute from Development Mechanism of Fractured-vuggy Reservoir in Carbonate Gas Reservoir in Sinian System Project (XNS14JS2013-035). We also thank the anonymous reviewers and editors for their constructive comments that have improved the manuscript.

Conflicts of Interest: The authors declare no conflict of interest.

\section{References}

1. Zou, C.N.; Guo, J.L.; Jia, A.L.; Wei, Y.S.; Yan, H.J.; Jia, C.Y.; Tang, H.F. Connotations of scientific development of giant gas fields in China. Nat. Gas Ind. B 2020, 7, 533-546. [CrossRef]

2. Anselmetti, F.S.; Eberli, G.P. Controls on sonic velocity in carbonate rocks. Pure Appl. Geophys. 1993, 141, 287-323. [CrossRef]

3. Lucia, F.J. Rock fabric/petrophysical classification of carbonate pore space for reservoir characterization. Am. Assoc. Pet. Geol. Bull. 1995, 79, 1275-13003.

4. Lucia, F.J. Carbonate Reservoir Characterization; Springer: New York, NY, USA, 1999.

5. Lucia, F.J. Carbonate Reservoir Characterization: An Integrated Approach, 2nd ed.; Springer: Berlin/Heidelberg, Germany, 2007.

6. Baechle, G.T.; Weger, R.; Eberli, G.P. Changes of shear moduli in carbonate rocks: Implication for Gassmann applicability. Lead. Edge 2005, 24, 507-510. [CrossRef]

7. Sun, Y.F.; Berteussen, K.; Vega, S.; Eberli, G.P.; Baechle, G.T.; Weger, R.J. Effects of pore structure on 4D seismic signals in carbonate reservoirs. In Proceedings of the 76th Annual International Meeting SEG, Expanded Abstracts, New Orleans, LA, USA, 15-18 October 2006; pp. 3260-3264.

8. Baechle, G.T.; Colpaert, A.; Eberli, G.P.; Weger, R.J. Modeling velocity in carbonates using a dual-porosity DEM model. In Proceedings of the 77th Annual International Meeting SEG, Expanded Abstracts, San Antonio, TX, USA, $23-26$ September 2007.

9. Booler, J.; Tucker, M. Distribution and geometry of facies and early diagenesis: The key to accommodation space variation and sequence stratigraphy: Upper Cretaceous Congost Carbonate platform, Spanish Pyrenees. Sediment. Geol. 2002, 146, 225-247. [CrossRef]

10. Morad, S.; Al-Aasm, I.S.; Nader, F.H.; Ceriani, A.; Gasparrini, M.; Mansurbeg, H. Impact of diagenesis on the spatial and temporal distribution of reservoir quality in the Jurassic Arab D and C members, offshore Abu Dhabi oilfield, United Arab Emirates. Geo Arab. 2012, 17, 17-56.

11. Yuan, D.Y.; Hou, J.R.; Song, Z.J.; Wang, Y.; Luo, M.; Zheng, Z.Y. Residual oil distribution characteristic of fractured-cavity carbonate reservoir after water flooding and enhanced oil recovery by $\mathrm{N} 2$ flooding of fractured-cavity carbonate reservoir. J. Pet. Sci. Eng. 2015, 129, 15-22. [CrossRef]

12. Aliakbardoust, E.; Rahimpour-Bonab, H. Effects of pore geometry and rock properties on water saturation of a carbonate res-ervoir. J. Pet. Sci. Eng. 2013, 112, 296-309. [CrossRef]

13. Zhao, L.; Nasser, M.; Han, D.-H. Quantitative geophysical pore-type characterization and its geological implication in carbonate reservoirs. Geophys. Prospect. 2013, 61, 827-841. [CrossRef]

14. Tonietto, S.N.; Margaret, Z.S.; Michael, P. Pore type characterization and classification in carbonate reservoirs. In Proceedings of the AAPG Annual Convention and Exhibition, Houston, TX, USA, 6-9 April 2014.

15. Anselmetti, F.S.; Eberli, G.P. Quantitative Characterization of Carbonate Pore Systems by Digital Image Analysis. Am. Assoc. Pet. Geol. Bull. 1998, 82, 1815-1836.

16. Lucia, F. Petrophysical Parameters Estimated from Visual Descriptions of Carbonate Rocks: A Field Classification of Carbonate Pore Space. J. Pet. Technol. 1983, 35, 629-637. [CrossRef]

17. Archie, G.E. Classification of carbonate reservoir rocks and petrophysical considerations. Am. Assoc. Pet. Geol. Bull. 1952, 36, 278-298.

18. Dürrast, H.; Siegesmund, S. Correlation between rock fabrics and physical properties of carbonate reservoir rocks. Acta Diabetol. 1999, 88, 392-408. [CrossRef]

19. Melim, L.A.; Anselmetti, F.S.; Eberli, G.P. The importance of pore type on permeability of Neogene carbonates, great Bahama bank. SPEM 2001, 70, 217-238.

20. Rafiei, Y.; Motie, M. Improved reservoir characterization by employing hydraulic flow unit classification in one of Iranian carbonate reservoirs. Adv. Geo-Energy Res. 2019, 3, 277-286. [CrossRef]

21. Hong, H.T.; Xie, J.R.; Wu, G.P.; Liu, X.; Fan, Y.; Xia, M.L.; Yang, Y.; Liu, X.; Chen, W.; Xia, M.L.; et al. The characteristics and development of marine carbonate reservoirs in Sichuan Basin, China. Acta Pet. Sin. 2012, A2, 64-73. (In Chinese)

22. Mo, J.; Wang, X.Z.; Leng, S.Y.; Lin, G.; Xiong, J.W.; Xie, L.; Zhou, Z. Reservoir characteristics and control Factors of Sinian Dengying Formation in central Sichuan. Geol. China 2013, 40, 1505-1514. (In Chinese) 
23. Zhou, Z.; Wang, X.Z.; Xie, L.; Mo, J.; Zhang, J. Reservoir features and physical influences of the Sinian Dengying Formation in central Sichuan, China. Nat. Gas Geosci. 2014, 25, 701-708. (In Chinese)

24. Zou, C.N.; Wei, G.Q.; Xu, C.C.; Du, J.H.; Xie, Z.Y.; Wang, Z.C.; Hou, L.H.; Yang, C.; Li, J.; Yang, W. Geochemistry of the Sinian-Cambrian gas system in the Sichuan Basin, China. Org. Geochem. 2014, 74, 13-21. [CrossRef]

25. Shan, X.Q.; Zhang, J.; Zhang, B.M.; Liu, J.J.; Zhou, H.; Wang, Y.J.; Fu, Z.W. Dolomite Karst reservoir characteristics and dissolution evidence of Sinian Dengying Formation, Sichuan Basin. Acta Pet. Sin. 2016, 37, 17-29. (In Chinese)

26. Wen, L.; Wang, W.Z.; Zhang, J.; Luo, B. Classification of Sinian Dengying Formation and sedimentary evolution mechanism of Gaoshiti-Moxi area in central Sichuan Basin. Acta Petrol. Sin. 2017, 33, 1285-1294. (In Chinese)

27. Xia, Q.S.; Huang, C.G.; Yuan, Y.R.; Peng, J.; Tao, Y.Z.; Zhou, X. Reservoir characteristics and main controlling factors of oil and gas accumulation of Dengying Formation, Sinian System, in Gaoshiti-Moxi area, Sichuan Basin. Geol. Rev. 2021, 67, 441-458. (In Chinese)

28. Cai, J.J.; Peng, X.; Li, Q.; Zhan, T.H.; Zhu, Z.M.; Li, W.; Gan, X.F.; Deng, Z.; Wang, J.S. Subdivision of strongly heterogeneous carbonate gas reservoir and technical countermeasures in different production stages: Case study of Sinian in Sichuan Basin. Nat. Gas Geosci. 2021, 32, 851-860. (In Chinese)

29. Si, C.S.; Hao, Y.; Zhou, J.G.; Ni, C.; Pan, L.Y. Characteristics and controlling factors of reservoir in Sichuan Dengying Formation, Sichuan Basin, China. J. Chengdu Univ. Technol. 2014, 41, 273. (In Chinese)

30. Luo, B.; Yang, Y.M.; Luo, W.J.; Wen, L.; Wang, W.Z.; Chen, K. Controlling factors and distribution of development in Dengying Formation of paleo-uplift in central Sichuan Basin. Acta Pet. Sin. 2015, 36, 416-426. (In Chinese)

31. Huang, W.M.; Liu, S.G.; Zhang, C.J.; Wang, G.Z.; Xu, G.S.; Yong, Z.Q.; Ma, W.X. The formation mechanisms of vug and characteristics of cements and fillings of Sinian system in Sichuan Basin. Pet. Geol. Exp. 2009, 31, 449-456. (In Chinese)

32. Liu, Q.; Zhu, D.; Jin, Z.; Liu, C.; Zhang, D.; He, Z. Coupled alteration of hydrothermal fluids and thermal sulfate reduction (TSR) in ancient dolomite reservoirs-An example from Sinian Dengying Formation in Sichuan Basin, southern China. Precambrian Res. 2016, 285, 39-57. [CrossRef]

33. Lee, S.H.; Datta-Gupta, A. Electrofacies characterization and permeability predictions in carbonate reservoirs: Role of multivariate analysis and nonparametric regression. In Proceedings of the SPE Annual Technical Conference and Exhibition, Houston, TX, USA, 3-6 October 1999.

34. Aguilera, M.S.; Aguilera, R. Improved models for perophysical analysis of dual porosity reservoirs. Petrophysics 2003, 44, 21-35.

35. Aguilera, R.F.; Aguilera, R. A triple porosity model for petrophysical analysis of naturally fractured reservoir. Petrophysics 2004, $45,157-166$.

36. Li, Y.; Anderson-Sprecher, R. Facies identification from well logs: A comparison of discriminant analysis and nave Bayes classifier. J. Pet. Sci. Eng. 2006, 53, 149-157. [CrossRef]

37. Liu, R.L.; Li, N.; Feng, Q.F.; Hai, C.; Wang, K.W. Application of the triple porosity model in well-log effectiveness estimation of the carbonate reservoir in Tarim oilfield. J. Pet. Sci. Eng. 2009, 68, 40-46. [CrossRef]

38. Yang, H.J.; Sun, S.Z.; Cai, L.L.; Xiao, Y.J.; Wang, H.Y.; Luo, C.S.; Hu, H.R. A new method of formation evaluation for fractured and caved carbonate reservoirs: A case study from the Lundong area, Tarim Basin, China. Pet. Sci. 2011, 8, 446-454. [CrossRef]

39. Dong, S.; Wang, Z.; Zeng, L. Lithology identification using kernel Fisher discriminant analysis with well logs. J. Pet. Sci. Eng. 2016, 143, 95-102. [CrossRef]

40. Al-Mudhafar, W.J. Integrating well log interpretations for lithofacies classification and permeability modeling through advanced machine learning algorithms. J. Pet. Explor. Prod. Technol. 2017, 7, 1023-1033. [CrossRef]

41. Wan, Y.; Zhang, H.; Liu, X.; Yin, G.; Xiong, J.; Liang, L. Prediction of mechanical parameters for low-permeability gas reservoirs in the Tazhong Block and its applications. Adv. Geo-Energy Res. 2020, 4, 219-228. [CrossRef]

42. Wang, Z.C.; Zhao, W.Z.; Peng, H.Y. Characteristics of composite petroleum-bearing systems in Sichuan Basin. Acta Pet. Sin. 2002, 29, 26-28. (In Chinese)

43. Wei, G.; Shen, P.; Yang, W.; Zhang, J.; Jiao, G.; Xie, W.; Xie, Z. Formation conditions and exploration prospects of Sinian large gas fields, Sichuan Basin. Pet. Explor. Dev. 2013, 40, 139-149. [CrossRef]

44. Xu, C.C.; Shen, P.; Yang, Y.M.; Luo, B.; Huang, J.Z.; Jiang, X.F.; Xie, J.R.; Cen, Y.J. Accumulation conditions and enrichment patterns of natural gas in the Lower Cambrian Longwangmiao Fm reservoirs of the Leshan-Longnvsi Palaeohigh, Sichuan Basin. Nat. Gas Ind. B 2014, 1, 51-57.

45. Wei, G.; Chen, G.; Du, S.; Zhang, L.; Yang, W. Petroleum systems of the oldest gas field in China: Neoproterozoic gas pools in the Weiyuan gas field, Sichuan Basin. Mar. Pet. Geol. 2008, 25, 371-386. [CrossRef]

46. Zhu, G.; Wang, T.; Xie, Z.; Xie, B.; Liu, K. Giant gas discovery in the Precambrian deeply buried reservoirs in the Sichuan Basin, China: Implications for gas exploration in old cratonic basins. Precambrian Res. 2015, 262, 45-66. [CrossRef]

47. Jiang, H.; Wang, Z.C.; Du, H.Y.; Zhang, C.M.; Wang, R.J.; Zou, N.N.; Wang, T.S.; Gu, Z.D.; Li, Y.X. Tectonic evolution of the Le shan-Longnvsi paleo-uplift and reservoir formation of Neoproterozoic Sinian gas. Nat. Gas Geosci. 2014, 25, 192-200. (In Chinese)

48. Awramik, S.M. Precambrian Columnar Stromatolite Diversity: Reflection of Metazoan Appearance. Science 1971, 174, 825-827. [CrossRef] [PubMed]

49. DU, J.; Zou, C.; Xu, C.; He, H.; Shen, P.; Yang, Y.; Li, Y.; Wei, G.; Wang, Z.; Yang, Y. Theoretical and technical innovations in strategic discovery of a giant gas field in Cambrian Longwangmiao Formation of central Sichuan paleo-uplift, Sichuan Basin. Pet. Explor. Dev. 2014, 41, 294-305. [CrossRef] 
50. Zhai, X.F.; Wang, Z.C.; Luo, P.; Wang, T.S.; Shi, S.Y.; Zhang, H. Characteristics and origin of microbial dolomite reservoirs in Upper Sinian Dengying Formation, eastern Gaoshiti area, Sichuan Basin, SW China. Nat. Gas Geosci. 2017, 28, 1199-1210. (In Chinese)

51. Wang, X.Z.; Chen, K.G.; Huang, J.X.; Fang, S.X.; Hou, F.H. A study on the chemical fillings in the secondary pores of the Sinian reservoir, Sichuan Basin. Acta Pet. Sin. 2001, 28, 41-47. (In Chinese)

52. Yao, G.S.; Hao, Y.; Zhou, J.G.; Jiang, W.X.; Wen, L.; Ni, C.; Pan, L.Y.; Zhang, J.Y. Formation and evolution of reservoir spaces in the Sinian Dengying Formation of the Sichuan Basin. Nat. Gas Ind. 2014, 34, 31-37. (In Chinese)

53. Zhou, J.G.; Yao, G.S.; Yang, G.; Zhang, J.Y.; Hao, Y.; Wang, F.; Gu, M.F.; Li, W.Z. Genesis mechanism of the Sinian-Cambrian Reservoirs in the Anyue Gas Field, Sichuan Basin. Nat. Gas Ind. 2015, 2, 127-135.

54. Hao, Y.; Yang, X.; Wang, Y.F.; Chen, W.; Gu, M.F.; Hou, G.F. Supergene karstification in the Sinian Dengying Formation, Sichuan Basin. Sediment. Geol. Tethyan Geol. 2017, 37, 48-54. (In Chinese) 